\title{
The treatment of adult patients with mental disability. Part 1: Consent and duty
}

\author{
A. M. Bridgman, 1 and M. A. Wilson, ${ }^{2}$
}

\section{Over recent years practitioners are increasingly being asked to attend to, or to provide treatment for, adult patients with some degree of mental illness, either in their homes or in the dental surgery. Demographic changes, an ageing population with increasing incidence of dementia, and the philosophy of 'care in the community' for those with long-term mental health problems will ensure that such requests will continue. Such requests present the practitioner with a number of ethical and legal problems. This series of papers looks at the legal issues that arise by reference to case scenarios in this area of 'special needs' dentistry. This first paper deals with the issue of consent, and the legal duty of care that arises on the part of the dentist when attending a patient who is unable to consent to treatment.}

$\mathbf{R}^{\text {ecently the number of patients with }}$ Rome degree of mental disability seeking dental care from the Community and General Dental Services, and perhaps ultimately the Hospital Service, is increasing. This has arisen as a result of the combined effect of the demographic trends of an ageing population and changes in the care philosophy of the long-term mentally ill. It is estimated that by the year 2008 over $75 \%$ of adults over 65 years will have retained some teeth. ${ }^{1}$ The retired account for around onefifth of the population and although the majority of over $65 \mathrm{~s}$ are neither mentally nor physically ill, depression and more importantly dementia are of significant concern. The philosophy of 'care in the community', in conjunction with the concept of 'social normalisation', prefers that patients with acquired mental disability, such as dementia, or patients with a learning disability live within their family unit or other local residential units, rather than in a geriatric unit, psychiatric hospital or other institutions. These patients' need for dental care, either

\footnotetext{
$1^{*}$ Clinical Teacher and Lecturer for Ethics \& Law, Turner Dental School, University of Manchester Dental Hospital, Higher Cambridge Street, Manchester M15 6FH; ${ }^{2}$ Consultant in Restorative Dentistry, Turner Dental School, University of

Manchester Dental Hospital, Higher Cambridge

Street, Manchester M15 6FH

${ }^{\star}$ Correspondence to: Andrew Bridgman REFEREED PAPER

Received 15.12.99; accepted 15.03.00

(C) British Dental Journal 2000; 189: 66-68
}

In brief

- The number of adults with mental disability seeking primary dental care is increasing.

- Some patients may not be able to give a valid consent.

- Treatment without consent is unlawful.

- No-one else can give consent on behalf of an adult patient.

- A dentist has a duty to help and provide care that is in the 'best interests' of patients unable to decide for themselves.

routine or occasional, is not diminished by their mental disability and as they live within the community it is likely that they, or at least their carers, will request the family dentist or the community dentist to provide dental care. While some patients may present the dentist with a variety of perplexing and complex problems in relation to their care, others will not. For many patients the provision of dental treatment poses few problems. Their mental disability does not affect their level of competence or their ability to participate in treatment decisions and they are able to receive treatment in the usual way. For other patients the capacity to decide for themselves may be severely compromised, they may have little or no understanding of treatment proposals. Some of these patients will, however, remain co- operative and compliant, accepting treatment without difficulty. Others may actively, and perhaps combatively, resist treatment.

This series of papers seeks to address the legal and ethical issues that arise during the treatment of adult dental patients who have some form of mental disability. By using case scenarios it is intended to illustrate the sort of situations encountered by dental practitioners. There are three areas of concern to be covered in this series:

1. Consent to treatment and the lawful treatment of patients incapable of giving consent. This is important where there is some doubt whether or not the patient is refusing, or appearing to refuse, treatment. This is perhaps a core issue in 'special needs' dental care.

2. Assessment of competence in the context of consent to treatment. This is a very important issue in the care of such patients because it seems that the law does not allow the dentist to simply walk away from a patient who has a mental disability and appears to be refusing treatment. It would be unacceptable, both ethically and legally, to accept the refusal at face value.

3. The use of restraint in the treatment of incompetent patients.

\section{Legal value of consent}

The value of a patient's agreement to treatment is that it recognises his or her right to decide for himself or herself. In addition, it provides a defence to an allegation of battery (more commonly called assault) in the tort of trespass to the person, which is defined as the intentional and direct touching of another person without their permission. 'It is well established that the performance of a medical operation on a person without his consent will be unlawful. ${ }^{2}$

\section{A valid consent?}

Case Scenaro 1 (see the Box on the next page) illustrates a situation where there may be some doubt about the patient's capacity to decide and to agree to the treatment being carried out. She appears to understand the dentist when he is talking to her but does not remember those discussions at 
a later date. Yet, she remains compliant throughout all the treatment. The question to be asked is, 'Is this patient competent?' If the answer is, 'Yes', then treatment proceeds lawfully by virtue of her consent and there is no problem. But what if she is not competent? If she is not competent, then her compliance or her signature will not signify consent; her 'consent' will not be valid and treatment without a valid consent is unlawful.

\section{The consent of another}

In this Case Scenario the daughter has also signed the consent form. Is the daughter's consent to the treatment adequate? If, as a result of mental incapacity an adult is unable to give a valid consent can anyone else consent to treatment on their behalf? In a case involving the prophylactic sterilisation of a 19-year-old woman who was severely mentally disabled a judge posed himself this very same question. And the answer is No! ${ }^{3}$ There is no provision for proxy consent for adults within the common law or within the Mental Health Act 1983, unlike its 1959 predecessor, and the Court relinquished its jurisdiction over persons of unsound mind in 1960.

Despite this being such a clear law there is evidence that doctors and dentists believe that someone else can give a valid consent on behalf of an adult patient of unsound mind. In a survey, 14 out 50 dentists thought someone else could sign a consent form on behalf of the patient. ${ }^{4}$ Some Social Services Departments have issued 'Guidelines on Service Users and Consent to Treatment'. The document clearly explains to its staff that they cannot give consent on behalf of the patient. They are advised to contact a senior manager if a doctor or dentist persists in asking them to provide consent for treatment. This misconception about proxy consent raises some major concerns. First, there is the concern that the dentist who operates with the consent of another believes that s/he is operating lawfully. The treatment that $\mathrm{s}$ /he provides may well be provided lawfully but it is not by virtue of that consent.

Second, there is the danger that the patient's mental capacity will not be fully tested if the dentist believes a lawful consent

\section{Case Scenario 1 - the compliant patient}

s part of a campaign to promote the health of its patients the matron of a nursAing home asks a local practitioner to attend the home for a routine screening of those patients without their own dentist. Examination of one patient, a 72-year-old lady with senile dementia, reveals many decayed teeth some of which are beyond restoration and although symptomless require extraction. Treatment is desirable because the extent of the decay suggests that the likelihood of future problems is high. There appears to be nothing complicated in the treatment which will consist of several restorations and some extractions. The patient is told of the need for treatment, what is to be done, and that arrangements will be made for her to visit the dentist's surgery at a later date. She appears to understand and seems to agree with the suggestions made to her by the dentist.

The patient arrives for her appointment, accompanied by her daughter, but seems to be confused and does not understand why she is there. She and her daughter are given another full explanation of the proposed treatment. Once again she appears to understand and following radiographic examination agrees to two extractions that day. The patient signs the usual consent form and the dentist also asks the daughter to sign the form. The teeth are removed under local anaesthesia without any problems.

At the second appointment once again the patient appears confused and uncertain why she is at a dental surgery. Once again following a full discussion she and her daughter agree to treatment and both sign a consent form for two more extractions. All subsequent visits are conducted in the same manner until treatment is complete.

can be given by another person. Faced with a patient who is resisting treatment the dentist who believes this may simply turn to a relative or carer for permission to carry on. The desire to relieve or prevent suffering is very powerful and can be difficult to resist. A dentist might be tempted to assume a patient incompetent without a proper assessment, and ignore their protests if it is believed that a proxy can authorise the necessary treatment. Such a misconception offers great potential for depriving the patient of their right to independent decision making - even if that means continued discomfort and the patient's choice seems inconsistent with their well-being.

Third, there is the concern that some dentists believe that only a proxy consent gives lawful authority to proceed with treatment. If no proxy consent is available then treatment of an incompetent patient may not proceed. In the above mentioned survey 13 out of 50 dentists said they would not provide treatment without a signed consent form. ${ }^{4}$ In addition, 9 dentists said that they would only provide treatment in the absence of consent after obtaining professional agreement about the proposed intervention. Unfortunately, there may be no relatives or carers at hand to sign the consent forms and the opinion of a professional colleague may not be immediately available. Clearly then a patient may be denied the necessary care, at least until a consent form can be signed or a second opinion arranged. Neither proxy consent or the opinion of a colleague will make the intervention lawful and such delay may expose the dentist to liability in negligence for a failing in their duty of care.

Last, there is the concern that the relative or carer may not necessarily be an appropriate person to decide on the patient's behalf. They may make choices that will allow treatments to proceed on the basis of convenience to themselves or, worse, on the basis of other ulterior motives such as cost.

\section{Lawful treatment}

A dentist who provides treatment without consent exposes himself to liability for battery in the tort of trespass to the person, thus it follows that a dentist who treats an adult patient who is incompetent and unable to give a consent would prima facie be liable for battery. To place those responsible for the health care needs of these patients in such a position is of course intolerable and this legal anomaly was addressed in 1989.

In a case involving the non-therapeutic and prophylactic sterilisation of a 36-yearold woman who had the mental capacity of a child aged 4 or 5 years and the verbal capacity of a child aged 2 years, the (Judicial) House of Lords determined that the court had the power to make a declaration that such an operation would be lawful. ${ }^{5}$ They further stated that such a declaration would not be necessary because any proposed operation on a mentally incompetent adult would be lawful provided that it could 
be considered, in the circumstances, to be in the best interests of the patients.

'At common law a doctor can lawfully operate on or give other treatment to adult patients who are incapable of consenting to his doing so, provided that the operation or treatment is in the best interests of such patients. The operation will be in their best interests only if it is carried out in order either to save their lives or to ensure improvement or prevent deterioration in their physical or mental health.'

\section{Doctrine of necessity}

The House of Lords based their declaration on the doctrine of necessity, and in essence it is the inability to communicate that best describes the nature of this doctrine. That inability may arise because there is insufficient time if effective action is to be taken, thus a man who seizes another and forcibly pushes him away from the path of an oncoming bus commits no wrong. The inability may arise because the other person is unable to communicate either because they are unconscious or because they suffer mental impairment which disables them from any, or complete, communication. It is necessary to distinguish between circumstances where the ability to communicate is temporarily absent, as in loss of consciousness, and circumstances where the ability to communicate properly is lost permanently. In the former situation the actions taken should be no more than is reasonably required to return the patient to a state of well-being. Where the situation is such that the patient is never going to be in a position to communicate properly and there is little point in waiting to obtain the patient's consent, the doctrine of necessity will extend to embrace that need for care which is obvious, including - 'such humdrum matters as routine medical or dental treatment, even simple care such as dressing and undressing, and putting to bed.'

\section{Best interests}

In Case 1 if the patient is incompetent then the dentist will not avoid liability for battery by virtue of the daughter's consent or her signature on the consent form. The dentist will only avoid liability if $s /$ he has acted in the patient's best interests. This does not mean that discussions with relatives and carers are not important. Indeed the law considers such discussions good practice, but they will not bind the dentist to act in accordance with them.

'Consultation with the next of kin has the further advantage in that it may reveal information as to the personal circumstances of the patient and as to the choice which the patient might have made... Neither the personal circumstances of the patient nor a speculative answer to the question "What would the patient have chosen?" can bind the practitioner in his choice of whether or not to treat or how to treat ...but they are factors to be taken into account by him in forming a clinical judgement as to what is in the best interests of the patient. ${ }^{8}$

The major factor in deciding if a dentist has acted in the patient's best interest would be whether the treatment provided was a treatment which a reasonable body of dental opinion would have considered appropriate in the circumstances. The 'best interests test' in the treatment of the incompetent adult dental patient is therefore the well-known professionally determined test of 'accepted practice' laid down in Bolam. ${ }^{9}$ In this respect clinical guidelines may be important. It is perhaps for this reason that some dentists will only provide treatment for an incompetent patient without consent after they have obtained a second professional opinion. Although such an approach may be regarded as prudent there

\begin{tabular}{|l|cccccc|}
\hline Table 1 & Legal references explained & & & \\
\hline & \multicolumn{7}{c|}{ Reported in: } \\
Name of case & Year reported & Vol. & Title & Page & Judge & At page \\
$T$ vT and another & {$[1988]$} & 1 & All ER & 613 & Wood & 617 \\
Glossary of titles: & All ER & All England Reports & & \\
\hline
\end{tabular}

is no legal requirement to do so. Should the patient's care be compromised by any delay in obtaining a second opinion then the dentist may have failed in their duty of care they may be liable in negligence.

\section{Summary}

In Case Scenario 1 the patient has a history of mental disorder and there is some doubt about her level of competence. Despite the fact that she appears to understand what is going on and is compliant she does not remember what the dentist has said from one visit to the next. Although many dentists may be concerned whether her consent is a valid consent or not, in a borderline case of mental competence like this it matters not. The dentist may lawfully provide treatment that will be justified either by the patient's consent or, provided that the treatment given is in the patient's best interests, by the doctrine of necessity.

The true dilemma for dentists treating borderline cases is deciding whether or not a patient who appears to be refusing treatment is in fact making no decision at all, or is making a valid refusal. It is a decision of considerable consequence as the dentist 'will be liable in damages if he fails to operate in accordance with the principle of necessity when there was no valid decision by the patient. ${ }^{\prime 10}$

The assessment of competence is clearly an important issue and will be the subject of the second paper in this series.

The following legal references are described in full in Table 1.

1 Department of Heath. An Oral Health Strategy for England. 1994

$2 \quad F v$ West Berkshire Health Authority [1989] 2 All ER 545 per Lord Goff at 563

3 T $v$ T and another [1988] 1 All ER 613 per Wood J at 617

4 Bridgman A M. The use of restraint for the provision of dental care. Dissertation submitted in fulfillment of the requirements for the degree of MA(Health Care Ethics and Law). University of Manchester, 1998 (unpublished)

$5 \quad$ Fv West Berkshire Health Authority [1989] 2 All ER 545

6 ibid. per curiam (the whole court)

7 ibid. per Lord Goff at 566

$8 \operatorname{Re} T$ [1992] 4 All ER 649 per Lord Donaldson at 653

9 Bolam v Friern Hospital Management Committee [1957] 2 All ER 118

10 Re T. supra. per Lord Staughton at 659 